\title{
Deambulando pelo santuário de panóias e pelos seus públicos: um estudo de caso.
}

\author{
Rute Teixeira $^{1}$
}

Resumo: $\mathrm{O}$ trabalho de investigação aqui enunciado, só foi possível num espaço culturalmente enriquecido por um legado histórico de extremo valor, como o Santuário de Panóias, localizado em Vila Real, que durante alguns anos recolheu informação sobre o perfil dos visitantes e o seu nível de satisfação com o Monumento. Este estudo teve como principais objetivos caraterizar os públicos que visitaram o Santuário entre 1996 e 1999 e entre 2006 e 2011, e ouvir as suas opiniões e propostas de melhoria. Para concretização destes objetivos foram construídos três instrumentos de investigação: inquérito por questionário, inquérito por entrevista e grelha de observação direta. A investigação desenvolveu-se entre a análise quantitativa e qualitativa e o cruzamento de dados mostrou-se fundamental em todo este processo. Tendo em conta o objetivo da investigação, concluímos que os públicos que, maioritariamente visitaram o Santuário de Panóias, no período analisado, foram o que Lopes (2004:45) designou nos seus trabalhos como Habituais. Assim, analogamente ao que Lopes (2004:46) referencia nos seus estudos, os públicos do Santuário de Panóias caraterizam-se por possuir habilitações académicas elevadas e profissões qualificadas, sendo detentores de um forte capital cultural já intrínseco e enraizado.

Palavras-chave: Públicos da cultura, valorização cultural, sítios patrimoniais, Santuário de Panóias.

\footnotetext{
${ }^{1}$ Doutoranda em Sociologia na Faculdade de Letras de Universidade do Porto, Portugal. Investigadora na área da sociologia da cultura e educação no Instituto de Sociologia da Faculdade de Letras da Universidade do Porto. E-mail: ruteateixeira@gmail.com
}

Latitude, Vol. 8, no 1, pp. 175-211, 2014

DOI: https://doi.org/10.28998/2179-5428.20140107 
Deambulando pelo santuário de panóias e pelos seus públicos: um estudo de caso.

\begin{abstract}
The research set out here, it was only possible in a culturally rich area for a historical legacy of extreme value, as Panóias Shrine, located in Vila Real, which for some years collected information on the profile of visitors and their level of satisfaction with the Monument. This study had two main objectives characterize the public who visited the Sanctuary between 1996 and 1999 and between 2006 and 2011, and listen to their opinions and suggestions for improvements. Questionnaire survey, interview survey and direct observation of grid: To achieve these objectives three research instruments were built. The research developed between the quantitative and qualitative analysis and the linking of data was essential in this process. Having regard to the purpose of the investigation, we conclude that public that mostly visited the Shrine of Panóias over that period, which were Lopes (2004:45) designated in its work as Usual. Thus, similarly to what Lopes (2004:46) reference in their studies, public Shrine Panóias are characterized by having high academic qualifications and professional jobs, being already in possession of a strong intrinsic and ingrained cultural capital.
\end{abstract}

Keywords: Public culture, cultural appreciation, heritage sites, Shrine Panóias.

\title{
1. Ensaios sociológicos em torno da cultura e da valorização do património
}

A literatura dos últimos anos permite-nos entender claramente que os autores contemporâneos se têm debruçado consideravelmente sobre os conceitos de cultura e de valorização do património histórico, devido ao valor intemporal que estes mantêm na sociedade atual, produto de um Mundo em constante mutação.

Esta bibliografia permite-nos constatar que atualmente existe uma maior consciência do valor histórico e da riqueza etnográfica do legado histórico coletivo, espelho de uma identidade cultural.

Daí a relevância que estas temáticas possuem na nossa sociedade, na medida em que se torna fundamental consciencializar os indivíduos para a importância da conservação, restauro e valorização do património cultural. 
Ao nível da temática da cultura encontramos autores como Ruíz (2006,p.190) que entende a valorização da cultura e do património cultural como um "elo de sustentação, de identificação, de herança e de riqueza histórica, bem como um suporte de diferenciação, atratividade e singularidade de uma região".

Desta forma, fica patente a importância preservar o património como forma de perpetuar a memória coletiva, como forma de dar a conhecer os valores culturais que transcendem a nossa Sociedade, como relíquias que trazem consigo o legado histórico e a identidade de uma Sociedade.

No entanto, ao abordarmos o conceito de valorização da cultura e de património cultural, há que evidenciar primeiramente o de cultura.

De acordo com documentação existente sobre o tema, frisamos que a cultura é fundamental para a compreensão dos diversos valores morais e éticos que guiam o comportamento social do Ser Humano, e que nos permite entender como estes valores se interiorizam na nossa consciência e conduzem as nossas emoções.

A literatura contemporânea salienta ainda o fato, de a cultura ser um fenómeno em constante evolução, muito diversificado e rico. No fundo, traduz-se num esforço coletivo pelo aprimoramento de valores espirituais e materiais que caracterizam um Povo.

Neste sentido, conclui-se que a cultura diz respeito a toda a criação diária que o Homem concretiza e que foi fruto das suas aprendizagens enquanto Ser Social.

Neste seguimento, Palomino at al (2005, p.6) encara que "devemos apreender a cultura como uma forma de revelação da Identidade de um Povo, que pode ser expressa através de fatos materiais e imateriais, reveladores da sua singularidade cultural".

Por outro lado, refletir sobre a importância da valorização do património cultural permite-nos fazer uma abordagem em termos de atratividade, autenticidade e diferenciação de uma região, condição através da qual esta será revalorizada em questão de imagem e de identidade.

Casasola (1990,p.31) argumenta que o "património cultural de uma região é constituído por todas as manifestações tangíveis e intangíveis produzidas na Sociedade, constituindo-se como fatores de identificação e de diferenciação de um Povo". 
Deambulando pelo santuário de panóias e pelos seus públicos: um estudo de caso.

O mesmo autor salienta que o património cultural inclui simultaneamente " monumentos, lugares e objectos representativos de um legado histórico, bem como exemplos da cultura, arte popular, tradições, costumes e valores de um Povo" (CASSASOLA,1990,p.31).

Neste senrido, a Carta de Veneza (1964), salienta que "o conceito de monumento histórico engloba, não só as criações arquitetónicas isoladamente, mas também os sítios, urbanos ou rurais, nos quais sejam patentes os testemunhos de uma civilização particular, de uma fase significativa da evolução ou do progresso, ou algum acontecimento histórico. Este conceito é aplicável, quer às grandes criações, quer às realizações mais modestas que tenham adquirido significado cultural com o passar do tempo".

Fica patente que património cultural é "fonte partilhada de memória, compreensão, identidade, coesão e criatividade" (CONVENÇÃO DE FARO, 2005).

Por outro lado, verifica-se uma evolução do conceito de património cultural, a partir do momento em que se valorizam a par de monumentos e arte, tradições e costumes centenários.

O conceito de património cultural imaterial foi promulgado pela UNESCO em 2003 através da Convenção para a Salvaguarda do Património Cultural Imaterial, onde foi reconhecida a necessidade de apoiar manifestações e expressões culturais que necessitariam de protecção jurídica.

Desta forma, costumes e tradições passaram a ser encarados com uma herança representativa de identidades coletivas e da diversidade cultural.

Nos seus trabalhos, Mamontoff (2010,p.158) define património cultural imaterial como sendo "práticas, manifestações, expressões e conhecimentos, que as comunidades e os indivíduos reconhecem como parte integrante do seu património cultural, o qual se vai transmitindo de geração em geração, recreando desta forma o meio social de onde provém, reforçando um sentimento de identidade e continuidade que promovem o respeito pela diversidade cultural e criatividade humana".

Segundo a UNESCO (2010) "o património cultural imaterial é uma riqueza muito importante", devendo ser preservado como forma de perpetuar a identidade e a histórica de um território", na medida em que "deverá assegurar a sustentabilidade futura de uma região, construindo e 
consolidando uma imagem credível e consistente, respeitando o património cultural enquanto bem não renovável". (BARATA, 2002,p.150); KLAMER,2000).

Sendo o Património Cultural um bem valioso para a Humanidade, a sua preservação, conservação e restauro torna-se uma prioridade nos dias de hoje, sendo também, uma responsabilidade para os Estados Políticos, que assumem compromissos internacionais no âmbito de organizações das Nações Unidas, enquanto membros.

Ao centrarmo-nos de seguida no caso Português, Jorge, (2000,p.6) defende que "a defesa e a conservação dos bens culturais são hoje reconhecidas como uma incumbência fundamental do Estado Português, apoiando-se na sua ampla conjuntura politica, social, económica, cultural e ambiental" cumprindo desta forma, compromissos internacionais assumidos com a Organização das Nações Unidas.

O Estado Português define como Património Cultural "todos os bens que, sendo testemunhos com valor de civilização ou de cultura portadores de interesse cultural relevante, devam ser objecto de especial proteção e valorização" (LEI DO PATRIMÓNIO CULTURAL, 2001).

É importante viver num País onde os bens culturais sejam entendidos como tesouros ou relíquias, portadores da história de cada Nação, que nos concedem uma identidade única, e que nos distinguem dos outros Povos, também eles portadores de uma vivência singular. Mas também, é fundamental que todos os cidadãos tenham a possibilidade de participar ativamente no usufruto do património cultural, como forma de desenvolvimento pessoal e de integração social, conferindo-lhes um sentimento de pertença, mas também de sabedoria e conhecimento, tao relevantes no incremento de uma consciência social ativa.

Vinuesa (2003, p.5) vai ao encontro destas ideias quando refere que "recuperar o património cultural requer um esforço de imaginação e de realismo, tentando encontrar novos equilíbrios nas realidades económicas e socias, instrumentalizando políticas que tenham como objetivo reforçar o compromisso social de preservação do deste legado histórico".

Neste âmbito, o património cultural tem cada vez um maior impacto na mobilização da população, sendo importante que a cultura, enquanto elemento transmissor de conhecimento e de valorização do indivíduo esteja á disposição de todos os públicos como fator de inclusão e de igualdade social. 
Deambulando pelo santuário de panóias e pelos seus públicos: um estudo de caso.

De acordo com a UNESCO (2001) "as políticas que favorecem a inclusão e a participação de todos os cidadãos garantem a coesão social, a vitalidade da sociedade civil e a paz". Só uma cultura inclusiva é que contribuirá para um efetivo desenvolvimento da sociedade e respetivos cidadãos.

Seguindo esta perspetiva "o desenvolvimento social ocorre, em primeiro lugar, pela valorização dos cidadãos que constituem uma sociedade, pelo respeito às suas práticas culturais e pelo acesso ao conhecimento" (BRANT,2002,p18). Assim sendo, cultura e sociedade estão inteiramente interligadas.

É neste campo que a "sociologia da cultura constitui uma aposta completa para analisar a permeabilidade da cultura nas diferentes realidades sociais, convidando-nos a repensar as disposições metodológicas que serão necessárias para incidir na emocionalidade humana" (ALEXANDER,2000,p.220).

Se cultura diz respeito a tudo aquilo que envolve o homem enquanto ser social, ficando este sujeito, à transmissão de valores morais e éticos, e de um legado histórico que por um lado, condiciona o seu desenvolvimento enquanto pessoa, e por outro, define a sua identidade, não se pode dissolvê-la do conceito de "públicos da cultura", na medida em que as dinâmicas sociais vão sofrendo mutações em função das variações culturais que emergem na sociedade.

Torna-se, desta forma, fundamental entender a questão dos públicos da cultura, pois segundo Santos (2004,p.80) esta perceção permite "que as instituições culturais e as instâncias políticas possam encontrar respostas adequadas para a momentosa questão dos novos públicos".

\section{Refletindo sobre os públicos da cultura}

O conceito de públicos da cultura, em termos genéricos, diz respeito a todos aqueles e aquelas suscetíveis de consumir atividades culturais. No entanto, cada autor aborda a temática de acordo com a sua perspetiva, verificando-se uma evolução em termos sociológicos deste conceito, ao longo dos tempos.

Falemos primeiramente de Bourdieu (2005,p.100), que "identifica os públicos da cultura na capacidade intelectual que têm na descodificação dos bens artísticos". O autor limita os públicos culturais a uma classe social dominante que, independentemente do seu perfil socioeconómico (apesar 
de dar mais enfoque às classes mais abastadas da sociedade), domina um maior capital social e/ou educacional por comparação com outras camadas da sociedade.

Gomes (2004:33) partilha da teoria de Bourdieu (2005,p.101), na medida em que concorda que "os lugares de classe correspondentes a recursos escolares elevados, bem como a elevada qualificação profissional se associam a uma maior probabilidade de consumo cultural regular e de frequência de eventos e equipamentos culturais" (GOMES, 2004,p.33).

Partindo deste pressuposto, Santos (2003,p.80) considera a existência de duas posições relativas aos públicos da cultura. A primeira apoia-se "de democratização do acesso aos patamares mais selectivos da criação e dos consumos culturais, que permanecem estreitamente correlacionados com o nível de instrução, e, por essa via, com a condição socioprofissional" (SANTOS,2003,p.82). A segunda posição apoia-se na "disseminação, do lado da oferta e da procura, das formas culturais mais próximas da cultura de entretenimento, audiovisual e mediática é, neste quadro, entendida como demonstrativa de uma reprodutibilidade pesada da "cultura de arte", cujo combate requererá o aperfeiçoamento dos processos de familiarização precoce e prolongada com os campos culturais mais seletivos" (SANTOS,2003,p.82).

Outro investigador da área entende que a análise dos públicos da cultura "pressupõe uma relação entre um conjunto de receptores mais ou menos activos e o campo da cultura objectivada e legitimada" (LOPES, 2004, p.44). Na opinião deste "assiste-se a uma ruptura face a um modelo estático e hierarquizado de classificação das culturas, modelo este assente numa oposição entre indivíduos cultos ou cultivados e incultos. A grande massa de camadas populares era, assim, vista segundo um padrão de negatividade em oposição ao das camadas cultas, que eram vistas de um modo hierarquicamente superior" (LOPES, 2000,p.35).

As tipologias criadas para definir públicos são variadas, como podemos comprovar após a análise de alguns estudos já efetuados por investigadores do Observatório das Atividades Culturais. Gomes (2004,p.32) a partir da análise de estudos realizados anteriormente, como o Festival Internacional de Teatro de Almada e no Evento Porto 2001 Capital da Cultura, distingui três categorias de públicos da cultura. Esta categorização foi efetuada com base na análise entre os capitais escolares dos públicos e as suas práticas culturais. Em primeiro lugar diferencia os 
Deambulando pelo santuário de panóias e pelos seus públicos: um estudo de caso.

públicos cultivados, que segundo o autor dizem respeito "á parcela do público em que é mais clara a articulação entre elevados recursos qualificacionais e a regularidade das práticas culturais" (GOMES,2004,p.33). São públicos que frequentam de uma forma mais intensiva a cultura em prol das suas elevadas qualificações académicas. Um segundo perfil diz respeito aos públicos retraídos, estes são compostos pela população com "recursos qualificacionais relativamente reduzidos e frágeis hábitos culturais" (GOMES, 2004,p.33). Ou seja, são públicos cujos hábitos culturais são extremamente reduzidos, estando estes relacionados com a diminuta qualificação escolar. Por fim, o autor define um terceiro perfil, públicos displicentes "caracterizados por elevadas qualificações, designadamente escolares, hábitos de saída convivial regulares, que se ligam a uma forte juvenilidade, e, ao mesmo tempo, pela rara frequência de eventos e equipamentos culturais" (GOMES, 2004,p.38). O autor define este público, como um "potencial público relativamente ao consumo de bens culturais" (GOMES, 2004,p.38).

Ainda sobre esta temática, abordaremos outro autor de grande relevo na caraterização dos públicos da cultura. Lopes (2004,p.44) classificou os públicos da cultura em três categorias. Um primeiro perfil, designados como habituais, "são os que têm menor representatividade na população portuguesa" (LOPES,2004,p.45). Dizem respeito, no geral, a indivíduos altamente escolarizados, qualificados e jovens, "prevalecendo disposições estéticas fortemente interiorizadas, fruto de um capital cultural consolidado" (LOPES,2004,p.45). Lopes (2004,p.46) designa como públicos irregulares os que são essencialmente "jovens e que frequentam de forma irregular os eventos culturais". O autor entende que "a escolaridade é uma condição necessária mas não suficiente para a prática cultural regular" (LOPES,2004,p.47). Estes jovens estão mais relacionados com as formas mediáticas de cultura, e estão sujeitos aos fenómenos de regressão, por duas vias: a familiar, através do retorno a situações de convivência com gerações muito menos escolarizadas; e a posicional, com tarefas rotineiras que desmobilizam potenciais competências de inovação e criatividade. Por fim, os públicos retraídos (denominação idêntica em ambos os autores) movem-se quase exclusivamente fora da esfera cultural. Estes caracterizamse pelo seu baixo capital escolar, e reduzida frequência nos eventos culturais. Estes públicos "movem-se quase exclusivamente na esfera das práticas doméstico-recetivas e de sociabilidade local" (LOPES, 2004,p.49). E 
acrescenta que estas "categorias são ideias-tipo, que podem eventualmente ser transversais, ou seja, um "público retraído face à cultura erudita, pode ser um público habitual de um outro tipo de cultura (popular, massificada, etc.) " (LOPES, 2004,p.49).

O mesmo autor refere a necessidade de "alargar e fidelizar novos públicos", no sentido de alcançarmos "patamares mínimos de democratização cultural" (LOPES, 2004,p.52). Este é um conceito atualmente importante e debatido, na medida e que nos permite refletir sobre estratégias de captação de novos públicos e de envolvimento de toda uma sociedade num processo de valorização da cultura enquanto fenómeno de valorização pessoal.

Se analisarmos o cerne desta questão, poderemos questionar: "Quem são os novos públicos da cultura?" Pelo que temos analisado na literatura, "novos" significa "mais dos mesmos". No fundo trata-se de um esforço em trazer mais pessoas aos eventos culturais. De facto, um grande desafio é colocado aos profissionais da cultura e à sociedade em geral. Como refere Vlachou (2011) um dos desafios dos ambientes culturais será o envolvimento das pessoas como proposta individualmente enriquecedora.

E desta forma, um breve eco tem elaborado a teoria de que os agentes terão de ser envolvidos na cena cultural, enquanto elemento estruturador e responsável pelo seu próprio desenvolvimento pessoal e social.

\section{Investigação empírica}

\subsection{O Santuário de Panóias}

A investigação que foi levada a cabo no âmbito da temática aqui desenvolvida, só foi possível ser concretizada num espaço culturalmente enriquecido por um legado histórico de extremo valor, como o Santuário de Panóias, em Vila Real.

O Santuário de Panóias, durante muitos anos denominado por Fragas de Panóias, está classificado como Monumento Nacional desde 1910, é propriedade do Estado, e está afeto à Direção Regional de Cultura do Norte. É conhecido desde o séc. XVIII (ARGOTE, 1734) e foi objeto de estudos e investigação até aos nossos dias, por parte de investigadores nacionais e estrangeiros, sendo que com os trabalhos e a interpretação de Géza Alfoldy (1997) foi possível de fato identificar este espaço como um espaço sagrado, um Santuário, da época romana, dedicado a Serápis, divindade oriental. 
Deambulando pelo santuário de panóias e pelos seus públicos: um estudo de caso.

Conservam-se hoje no lugar várias rochas talhadas, tendo três delas sido templos. Também se conservam numa delas quatro inscrições, uma em grego e três em latim, dedicadas a divindades.

Restam também as diferentes cavidades retangulares que serviam para queimar as vísceras, uma cavidade redonda-gastra, para assar a carne, e ainda uma outra onde se procedia à limpeza do sangue, gordura e azeite. Outras cavidades estavam relacionadas com os pequenos templos existentes, e destinar-se-iam a guardar os instrumentos sagrados usados nos rituais.

Temos, portanto em Panóias testemunhos de um rito de iniciação dos mistérios das divindades infernais. As prescrições identificam-se como partes de uma lei sagrada, mas aplicadas a um local concreto e preciso.

A escolha deste local não foi, portanto feita ao acaso, mas sim fruto de critérios específicos e previamente estabelecidos.

\subsection{Metodologia}

A presente investigação foi desenvolvida no âmbito do mestrado em Ciências da Educação em parceria com a Direção Regional de Cultura do Norte e pretendeu averiguar: "Quais os Públicos visitantes do Santuário de Panóias, e qual a sua opinião sobre o Monumento?".

O estudo de caso foi a estratégia de investigação utilizada no desenvolvimento deste trabalho. Para Yin (1993,p.32) "um estudo de caso é uma investigação empírica que investiga um fenómeno contemporâneo dentro do seu contexto de vida real, especialmente quando os limites entre o fenómeno e o contexto não estão claramente definidos". Também Yacuzzi (2005,p.299), em relação aos estudos de caso refere que" (...) o seu valor reside em que não apenas se estuda um fenómeno, mas também o seu contexto. Isto implica a presença de tantas variáveis que o número de casos necessários para as tratar estatisticamente seria impossível de estudar".

O estudo de caso rege-se dentro da lógica que guia as "sucessivas etapas de recolha, análise e interpretação da informação dos métodos qualitativos, com a particularidade de que o propósito da investigação é o estudo intensivo de um ou poucos casos" (LATORRE at al., 2003,p.230).

A vantagem do estudo de caso é a sua "aplicabilidade a situações humanas, a contextos contemporâneos de vida real" (DOOLEY, 2002,p.334). Dooley (2002,p.333) refere ainda que "investigadores de várias disciplinas usam o método de investigação do estudo de caso para 
desenvolver teoria, para produzir nova teoria, para contestar ou desafiar teoria, para explicar uma situação, para estabelecer uma base de aplicação de soluções para situações, para explorar, ou para descrever um objeto ou fenómeno".

A metodologia de qualquer estudo de investigação deve ser definida com base nas questões que se pretendem investigar, na medida em que são estas que determinam o quadro concetual e a metodologia a seguir. Desta forma, a investigação pode adquirir um "cariz quantitativo, qualitativo ou ainda a conjugação de ambos" (GUERREIRO, 2003,p.34).

Segundo Rocha (1999,p.23) o investigador que se coloca na "perspectiva quantitativa, valoriza mais os resultados que os processos, acredita na objectividade da avaliação" e coloca-se fora da subjetividade dos fenómenos culturais valorizando mais o carácter estável do que o dinâmico da realidade.

Por sua vez, um investigador que recorre à investigação qualitativa considera a cultura sempre ligada a valores, problematiza a objetividade da avaliação, valoriza mais os processos do que os resultados e mais o caráter dinâmico e subjetivo da realidade.

Embora, o paradigma qualitativo esteja a ganhar terreno em relação ao quantitativo, um grande número de autores chama a atenção para as vantagens que se podem obter com "a combinação de métodos vindos dos dois paradigmas" (FRAGOSO, 2000,p.16).

É o caso deste estudo, cujos dados recolhidos primariamente foram de natureza quantitativa e qualitativa, sendo os últimos utilizados num contexto meramente descritivo.

Para evitar enviesamentos, aconselha-se que neste tipo de investigação, "sejam utilizadas três técnicas de recolha de dados: inquéritos (por entrevista e/ou por questionário), observação directa e análise de documentos" (MERRIAM, 1988,p.120).

Atendendo ao âmbito da presente investigação e aos seus objetivos, os instrumentos utilizados para a recolha de dados foram: inquérito por entrevista, inquérito por questionário e grelha de observação direta.

Esta observação foi construída com base num modelo analítico teórico-prático, na medida em que os dados recolhidos foram trabalhados posteriormente e, em conformidade com os que primariamente emergiram da interação com os atores sociais. 
Deambulando pelo santuário de panóias e pelos seus públicos: um estudo de caso.

\subsection{Construção dos instrumentos de recolha de dados}

Para a realização deste estudo foram construídos instrumentos de investigação que se adaptassem aos objetivos da pesquisa.

Esses instrumentos foram:

- Inquérito por questionário (aplicado a todos os visitantes do Santuário de Panóias);

- Inquérito por entrevista (aplicado ao Responsável e Guia do Santuário de Panóias);

- Grelha de observação direta (utilizada para observar no "terreno" aspetos de grande relevo).

\subsection{Inquérito por questionário}

“O questionário é tanto um ponto de chegada de uma reflexão como o ponto de partida para análises ulteriores" (ALBARELO,1997,p.85) e, segundo Tuckman (2000,p.100), é "utilizado pelos investigadores, para transformar em dados a informação recolhida mediante interrogação de pessoas (ou sujeitos) e não observando-as ou recolhendo amostras do seu comportamento".

Através deste processo, é possível medir o que uma pessoa sabe (informação ou conhecimento), o que gosta e não gosta (valores e preferências) e o que pensa (atitudes e crenças).

O mesmo autor considera ainda que "esta informação pode ser transformada em números ou dados quantitativos, utilizando técnicas de escalas de atitudes e escalas de avaliação, contando o número de sujeitos que deram determinada resposta, dando assim origem a dados de frequência" (TUCKMAN,2000,p.102).

A construção do inquérito por questionários, não foi da responsabilidade do investigador, mas sim da Direção Geral de Cultura do Norte, que elaborou dois modelos a serem aplicados em momentos diferentes: um entre 1996 e 1999 e o seguinte entre 2006 e 2011.

Os dois exemplares utilizaram os seguintes tipos de questões:

-Questões abertas, em que o "sujeito responde a uma questão com as suas próprias palavras" (DAMAS \& DE KETELE, 1985,p.24);

-Questões semifechadas (questões de cafeteria), "possibilitando aos inquiridos não só da produção de algumas propostas" (dada a impossibilidade de sermos exaustivos nos itens por nós propostos) como 
também a valorização das suas próprias opiniões" (DAMAS \& De KETELE, 1985,p.56);

-Questões de "produção numerada e escolha múltipla", (DAMAS \& De KETELE, 1985,p.67), a partir das quais foi possível a caraterização da amostra.

Relativamente ao processo de amostragem, do qual depende a validade que permite a posterior generalização de resultados, não deve ser deixada ao acaso, pois pretender-se uma amostra o mais representativa possível. Nesta Investigação o universo da amostra contou com 711 indivíduos.

Desta forma, para evitar a distorção dos resultados, tivemos o cuidado de encorajar os visitantes a responder individualmente ao inquérito, após finalizarem a visita ao Santuário de Panóias.

Designamos por inquérito $\mathrm{A}$, aquele que foi aplicado no período entre 1996 e 1999 e entre 2006 até 2009; o inquérito B ao que foi introduzido durante os anos de 2010 e 2011.

O inquérito A teve como objetivos:

- Caraterização dos inquiridos relativamente ao sexo e a localidade de onde provinham;

-A perceção dos visitantes em relação a aspetos positivos do Santuário de Panóias;

-A opinião dos inquiridos quanto aos aspetos susceptiveis de melhorarias no Santuário de Panóias;

-Avaliação global da visita numa escala entre "Muito fraco" e "Muito bom".

$\mathrm{O}$ inquérito $\mathrm{B}$ teve como objetivos:

- Caraterização dos inquiridos, relativamente ao sexo, profissão e localidade de onde eram provenientes;

- A perceção dos visitantes acerca do Santuário de Panóias, através de um conjunto de questões, onde estes tinham de avaliar numa escala de "Muito fraco" a "Muito Bom": as acessibilidades, as instalações, o atendimento ao público, o material de apoio e a interpretação só sítio;

-Avaliação global da visita numa escala entre "Muito fraco" e "Muito bom".

Mediante a análise dos 711 inquéritos, que constituíram a amostra do estudo, foi possível categorizar diferentes dimensões relativas ao 
Deambulando pelo santuário de panóias e pelos seus públicos: um estudo de caso.

Santuário de Panóias (Quadro 1: Teixeira, 2013:67), sendo estas o suporte da análise e da conclusão dos resultados finais da investigação.

Quadro no 1 Dimensões analisadas no Santuário de Panóias

\begin{tabular}{l|l}
\hline Categorias & Subcategorias \\
\hline & $\begin{array}{l}\text { Receção ao visitante } \\
\text { Dunfinninnolinmm n nimmotin don }\end{array}$ \\
\hline Acolhimento
\end{tabular}

Visita Guiada

Acessos ao Santuário Acessibilidades

Entonionnmonto

Sinalética

\begin{tabular}{l|l} 
Apresentação do espaço & Limpeza
\end{tabular}

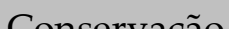

Divulgação

Recursos Didáticos $\quad$ Apresentação multimédia

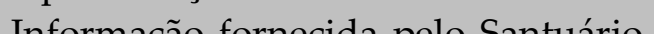

Melhorias sentidas

Interesse para a cultura e Sociedade

FONTE: TEIXEIRA (2013, p.67) 


\subsection{Inquérito por entrevista}

"A entrevista é um método de recolha de informações que consiste em conversas orais, individuais ou de grupos, com várias pessoas selecionadas cuidadosamente, a fim de obter informações sobre factos ou representações, cujo grau de pertinência, validade e fiabilidade é analisado na perspectiva dos objectivos da recolha de informações" (DE KETELE \& ROGIERS, 1999,p.150).

Para investigar um leque de aspetos relevantes acerca do Santuário de Panóias, tais como o seu funcionamento, barreiras arquitetónicas que prejudicam a circulação durante a visita, contributo para a cultura e sociedade portuguesa, foi aplicada a entrevista por permitir a obtenção de respostas diretas e informações mais completas.

Neste estudo, em particular, foi importante a entrevista porque "ajuda-nos a melhorar o nosso conhecimento do terreno e pode, ainda, fazer surgir questões insuspeitas que ajudarão o investigador alargar o seu horizonte e a colocar o problema da forma mais correcta possível" (QUIVY \& CAMPENHOUDT, 2003,p.45).

“O planeamento da entrevista é uma situação que se impõe como em qualquer outra tarefa de investigação" (CARMO \& FERREIRA, 1998,p.234).

Para as entrevistas foram planeadas os seguintes procedimentos: a definição de objetivos, bem como a construção de um guião, no qual foram operacionalizadas as categorias adequadas à investigação em curso.

Como um dos objetivos deste estudo foi também compreender o funcionamento do Santuário de Panóias nas suas diferentes dimensões, bem como considerar estratégias a programar como forma de promover o se crescimento e o desenvolvimento deste, enquanto Património Nacional, resolvemos entrevistar o responsável pela gestão do Monumento, bem como o único funcionário existente - guia do Santuário.

A entrevista A, aplicada ao responsável pela gestão do Santuário de Panóias, foi subdividida em dezassete questões, nas quais o entrevistado teria de apontar os aspetos positivos, aspetos negativos e melhorias a implementar nas diferentes vertentes. Estas centraram-se nos seguintes aspetos: acolhimento, profissionalismo dos funcionários, visita guiada, acessibilidades, estacionamento, sinalética, limpeza, conservação do espaço, organização do espaço, vedação, infraestruturas de apoio, vestígios 
Deambulando pelo santuário de panóias e pelos seus públicos: um estudo de caso.

arqueológicos, divulgação, recursos didáticos, informação fornecida pelo Santuário, melhorias sentidas ao longo dos tempos e Interesse para a cultura e sociedade portuguesa.

A entrevista B, aplicada ao guia do Santuário de Panóias, foi baseada nas mesmas dimensões que a Entrevista A, no entanto o entrevistado teria que dar apenas o seu parecer em relação a esses aspetos, focando algumas opiniões que lhe foram transmitidas pelos visitantes.

Na elaboração do guião de entrevista, tivemos em consideração as pessoas a serem entrevistadas e a função que desempenhavam no local selecionado para o estudo. Durante a realização da entrevista houve a preocupação de fornecer aos entrevistados uma breve explicação acerca da finalidade de cada conjunto de questões.

A maioria das questões formuladas eram de formato aberto, terminando algumas na forma "porquê?", "para evitar respostas curtas com pouca especificidade e para incentivar o entrevistado a aprofundar certos aspectos particularmente importantes" (QUIVY \& CAMPENHOUDT, 2003,p.70).

\subsection{Grelha de observação direta}

Segundo os teóricos, os "métodos de observação directa constituem os únicos métodos de investigação que captam os comportamentos no momento em que eles se produzem, sem a mediação de um documento ou de um testemunho" (QUIVY \& CAMPENHOUDT, 2003,p.72). Desta forma, o investigador pode estar atento ao aparecimento ou à transformação dos comportamentos, aos efeitos que eles produzem e aos contextos em que são observados.

A observação direta e participante foi também utilizada neste estudo, dado que o próprio investigador procedeu diretamente à recolha de algumas informações. Neste caso, a observação incidiu sobre as dimensões mencionadas anteriormente, e teve como suporte uma grelha que foi construída a partir desses indicadores.

Pretendeu-se com verificar quais os itens que se destacaram no contexto de uma visita ao Santuário de Panóias. Neste instrumento foi introduzido uma escala que variou entre "Insuficiente" e "Muito bom", com o objetivo de o investigador avaliar de forma precisa todas as dimensões propostas. 


\subsection{Recolha de dados}

A seleção destes instrumentos de recolha de dados justificou-se pelo facto de os mesmos garantirem "a recolha de informação sobre os pontos mais relevantes da investigação, tornar mais específicos os objetivos da investigação e motivar o entrevistado de modo a que pudesse partilhar aspectos importantes para a investigação" (MERRIAM, 1988,p.24).

Como anteriormente referido, no final de cada visita ao Santuário de Panóias, solicitava-se a cada visitante o preenchimento de um inquérito por questionário, com o objetivo de procedermos a uma posterior análise dos dados.

A aplicação dos questionários ocorreu entre dois períodos distintos: 1996 a 1999 e 2006 a 2011.

Os dados resultantes das entrevistas ao Gestor do Santuário de Panóias e ao respetivo Guia foram recolhidos em dezembro de 2011, após marcação prévia.

\subsection{Tratamento e análise de dados}

Para o tratamento dos dados, utilizaram-se como métodos de análise a estatística descritiva e a análise de conteúdo. Desta forma, os dados recolhidos através dos inquéritos por questionário (A-B) foram tratados através da estatística descritiva, enquanto os dados recolhidos através dos inquéritos por entrevista, e grelha de observação, foram tratados através da análise de conteúdo.

\section{Caraterização sociodemográfica da amostra}

A amostra para esta investigação foi recolhida entre 1996 e 1999 e entre 2006 e 2011 e contou com 711 inquiridos, aos quais foi aplicado o inquérito por questionário, após o término da visita guiada ao Santuário. 
Deambulando pelo santuário de panóias e pelos seus públicos: um estudo de caso.

\section{Gráfico $\mathrm{n}^{\mathrm{0}}$ 1: Classificação por sexo dos inquiridos}

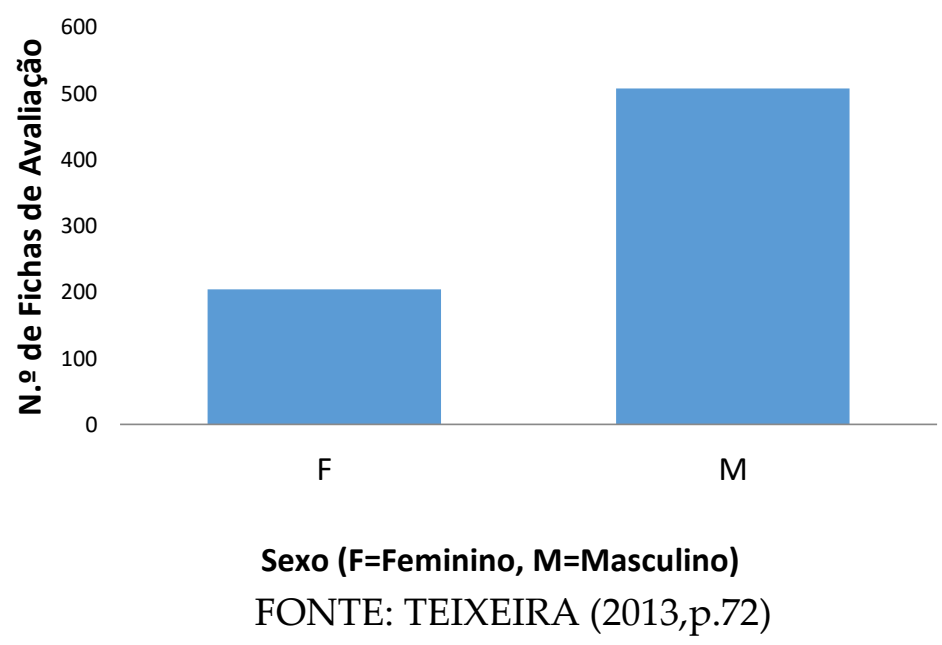

Num universo de 711 questionários analisados entre 1996 a 1999 e 2006 a 2011, confere-se que 28,7\% (n=204) dos visitantes pertencem ao sexo feminino e $71, \%(n=507)$ ao sexo masculino. Desde já notamos uma grande discrepância que foi melhor entendida nas entrevistas realizadas. Ou seja, não havia preocupação do Monumento em solicitar a participação de todos os visitantes, assim quando viajavam em grupo, geralmente quem preenchia o inquérito era o elemento masculino. Embora não se retirem dados concretos sobre o género dos visitantes, a análise deste gráfico e o entendimento da diferença entre o género dos visitantes, permitiu que no futuro a preocupação aumentasse quanto ao preenchimento dos questionários. 


\section{Gráfico no2: Distribuição geográfica dos visitantes estrangeiro}

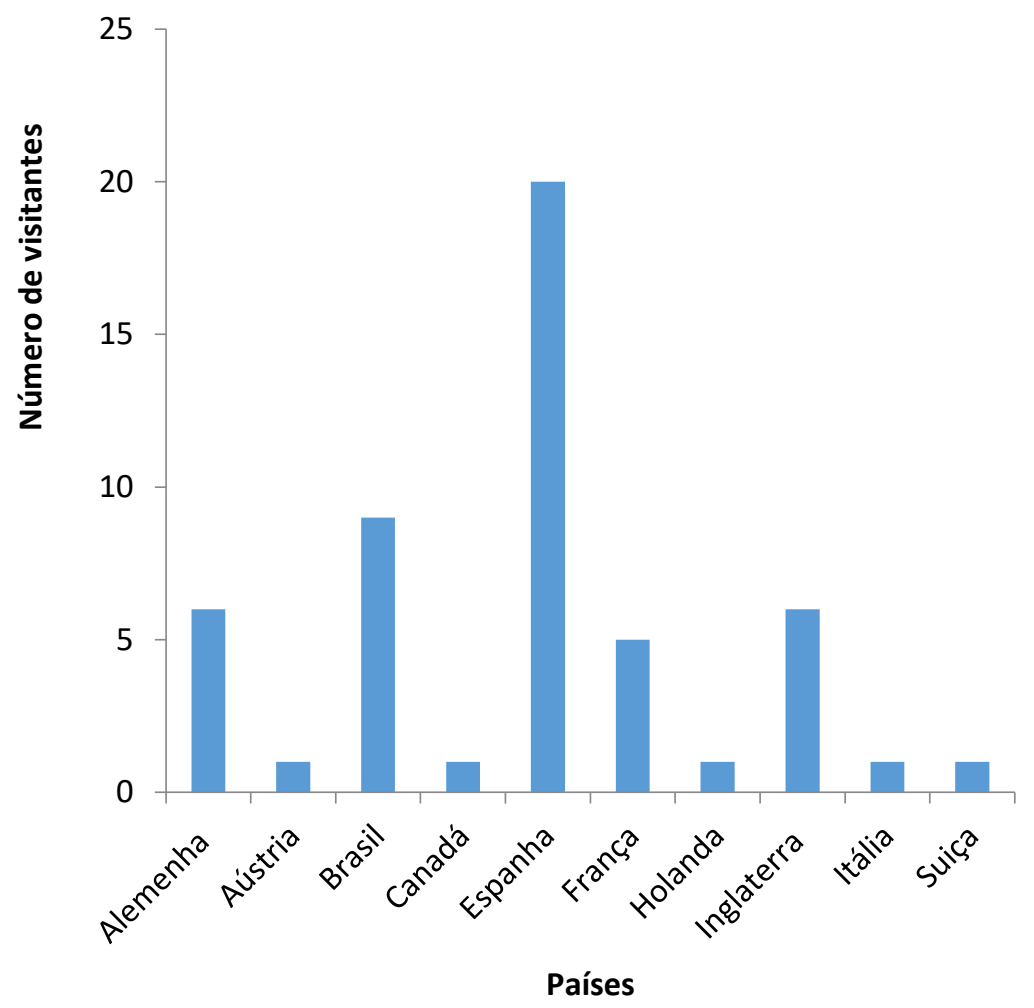

FONTE: TEIXEIRA (2013,p:73)

No que concerne à nacionalidade dos inquiridos, constata-se um predomínio de visitantes portugueses, $83,2 \%(n=592)$ em contraponto com $16,8 \% \quad(\mathrm{n}=119)$ de visitantes de nacionalidade estrangeira. Dos 119 inquiridos de nacionalidade estrangeira, apenas 45 divulgaram o seu país de origem, dos quais destacamos 20 espanhóis, 9 brasileiros, 6 alemães, 6 ingleses, 1 austríaco, 1 canadense, 1 italiano e 1 suíço. Note-se que a visita de estrangeiros é muito parca pelo que nos aponta para uma diminuta informação nas redes turísticas locais, regionais ou nacionais. 
Deambulando pelo santuário de panóias e pelos seus públicos: um estudo de caso.

\section{Gráfico nº3: Distribuição geográfica dos visitantes portugueses}

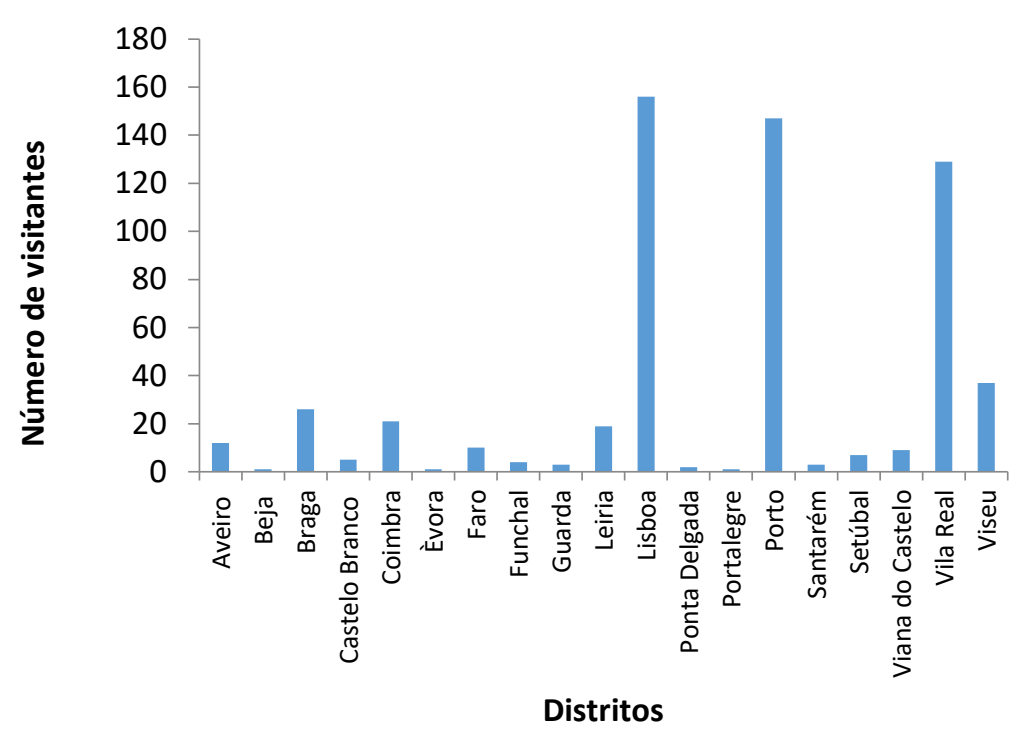

FONTE: TEIXEIRA (2013,p:74)

Dos 592 visitantes portugueses constata-se que 26,4\% (n=156) provém do distrito de Lisboa, 24,8\% ( $\mathrm{n}=147)$ do distrito do Porto, 21,8\% $(n=129)$ do distrito de Vila Real, 6,3\% $(n=37)$ do distrito de Viseu, 4,4\% $(\mathrm{n}=269$ do distrito de Braga, 3,5\% ( $\mathrm{n}=21)$ do distrito de Coimbra, 3,2\% $(\mathrm{n}=19)$ do distrito de Leiria, 2,0\% $(\mathrm{n}=12)$ do distrito de Aveiro, 1,7\% ( $\mathrm{n}=10)$ do distrito de Faro, 1,5\% ( $\mathrm{n}=9)$ do distrito de Viana do Castelo, 1,2\% ( $\mathrm{n}=7)$ do distrito de Setúbal, 0,8\% $(n=5)$ do distrito de Castelo Branco, 0,5\% ( $n=3)$ do distrito de Santarém, 0,5\% ( $\mathrm{n}=3)$ do distrito da Guarda, 0,7\% $(\mathrm{n}=4)$ do distrito do Funchal, 0,3\% ( $n=2)$ do distrito de Ponta Delgada, 0,2\% $(n=1)$ do distrito de Portalegre, $0,2 \%(n=1)$ do distrito de Évora.

Observa-se, assim, uma predominância de visitantes das grandes áreas urbanas, Porto e Lisboa, e do próprio distrito onde o monumento se localiza. Os públicos das restantes áreas nacionais é muito restrito. Aqui podemos destacar a questão da falta de informação e da sua distribuição 
pelo território nacional ou, por outro lado, a falta de interesse dos públicos fora das grandes áreas urbanas.

\section{Gráfico n⿳⺈:4: Profissão dos inquiridos}

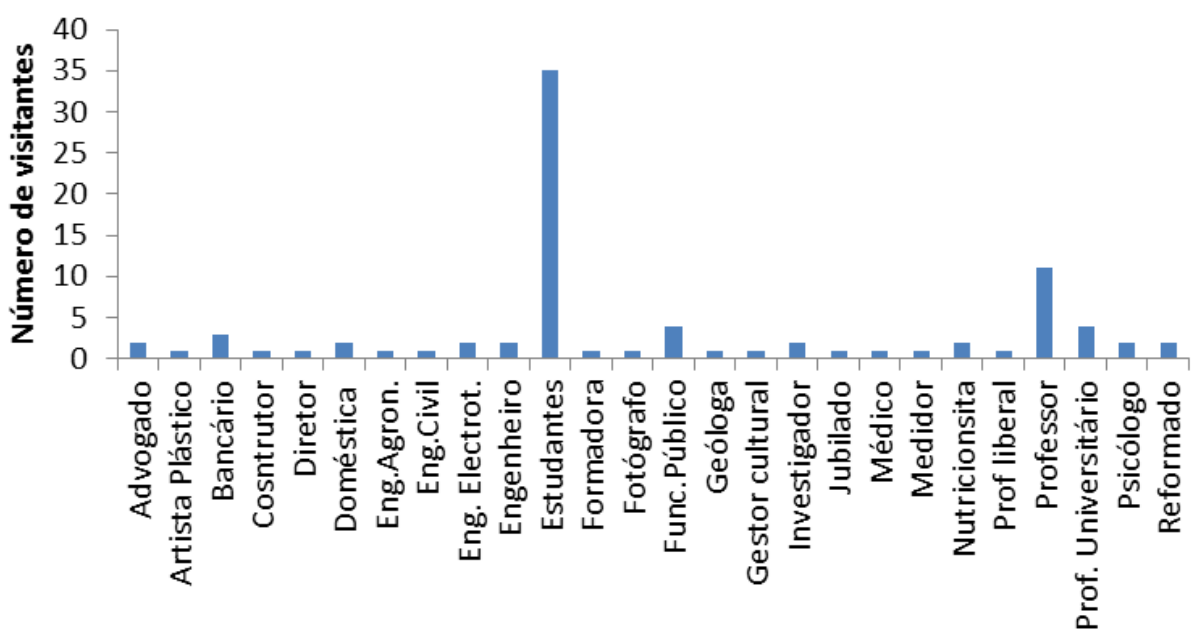

Profissões

FONTE: TEIXEIRA (2013,p:75)

Dos 711 visitantes que contemplaram o universo da amostra, $88 \%$ ( $n=624)$ não mencionaram a sua profissão. Note-se que a enorme lacuna que acompanha esta situação e permite, mais uma vez, concentrar a atenção no preenchimento dos questionários e na sensibilização do público para os mesmos.

Dos $12 \%$ que responderam $(n=87)$, pode-se constatar que existe uma vasta variedade em termos de estrutura profissional dos visitantes. De acordo com o Gráfico $\mathrm{n}^{\mathrm{o} 4}$, 40\% $(\mathrm{n}=35)$ dos inquiridos são estudantes, $17 \%$ $(n=11)$ são professores, $9 \%(n=6)$ são engenheiros, $5 \%(n=4$ são professores universitários), $5 \% \quad(\mathrm{n}=4)$ são funcionários públicos), 3,4\% $(\mathrm{n}=3)$ são bancários, 2,2\% (n=2) são psicólogos, 2,2\% (n=2) são reformados, 2,2\% (n=2) são nutricionistas, 2,2\% $(\mathrm{n}=2)$ são investigadores, 2,2\% $(\mathrm{n}=2)$ são domésticos, 2,2\% ( $\mathrm{n}=2)$ administradores, 1 é profissional liberal, 1 é medidor orçamentista, $1,1 \%(n=1)$ é médico, $1,1 \%(n=1)$ é jubilado, $1,1 \%$ $(\mathrm{n}=1)$ é geólogo, $1,1 \%(\mathrm{n}=1)$ é gestor cultural, $1,1 \%(\mathrm{n}=1)$ é fotógrafo, $1,1 \%$ 
Deambulando pelo santuário de panóias e pelos seus públicos: um estudo de caso.

$(\mathrm{n}=1)$ é formador, $1,1 \%(\mathrm{n}=1)$ diretor, $1,1 \%(\mathrm{n}=1)$ consultor, $1,1 \%(\mathrm{n}=1)$ artista plástico e 1,1\% (n=1) advogado.

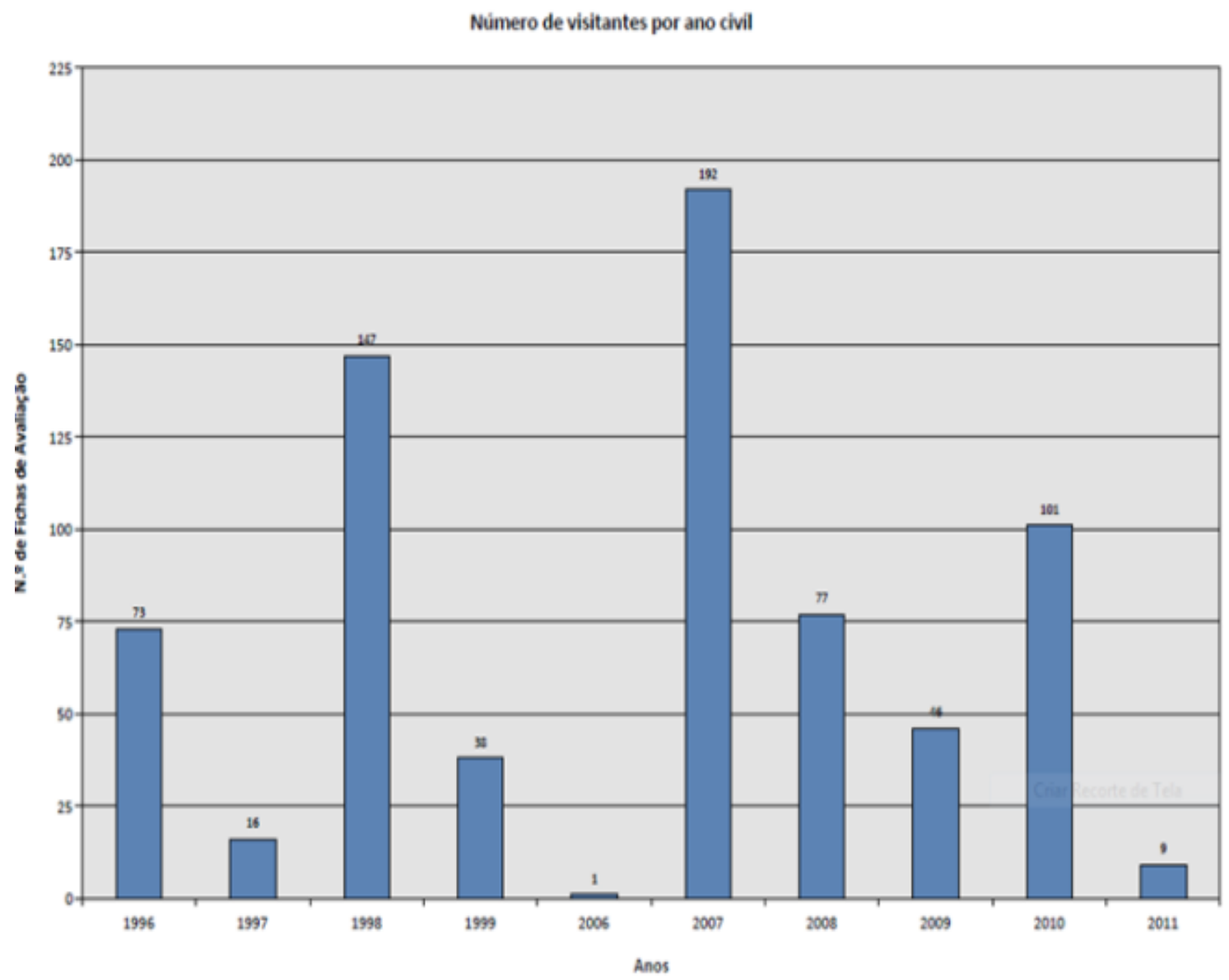

Gráfico no5: Número de visitantes por ano civil FONTE: TEIXEIRA (2013,p 76)

Analisar o número de visitantes ao Santuário de Panóias tornou-se preponderante para a nossa investigação, pelo facto de se terem registado variações consideráveis no número de visitas ao longo dos anos.

O período de análise contemplado ocorreu entre os anos de 1996 e 1999 e entre 2006 e 2011. Este interregno na aplicação dos questionários deveu-se ao facto de terem ocorrido no Monumento algumas mudanças em termos logísticos, que contribuíram para uma total ausência de respostas 
neste período, e para uma variação considerável da aplicação do mesmo, ao longo dos restantes anos.

No entanto é de ressalvar, que em certos casos, visitantes recusaram o preenchimento do Inquérito, e em grupos numerosos, regra geral, apenas uma pessoa é que preenchia o documento.

Constatou-se que no ano de 1996 visitaram o Santuário de Panóias 73 visitantes, em contrapondo com o ano de 1997, em que apenas 16 visitantes estiverem presentes no monumento.

Em 1998, o número de visitantes aumentou significativamente para 147; já em 1999 verificou-se uma quebra para 38 visitantes.

Em 2006, o Santuário de Panóias contou apenas com a presença de 1 visitante; este número disparou em 2007 para 192 visitantes. Voltou a sentir-se uma quebra nos anos de 2008 e 2009, onde o monumento contou apenas com 77 e 46 visitantes prospectivamente.

Em 2010 estes valores voltaram a subir para 101 visitantes e, em 2011 apenas de verificou a presença de 9 visitantes.

\section{Apresentação dos resultados empíricos}

\subsection{Avaliação global do Santuário de Panóias pelos inquiridos}

Um dos principais objetivos deste trabalho foi questionar os visitantes a respeito da sua satisfação global no que concerne à visita ao Monumento.

Esta análise, conforme anteriormente referido, foi baseada nos parâmetros incluídos nos dois inquéritos desenvolvidos pela Direção Regional da Cultura do Norte: acessibilidades, condições materiais do espaço, atendimento ao público, materiais de apoio, interpretação do sítio, aspetos positivos e aspetos negativos do Monumento.

De forma geral, podemos concluir que a opinião dos inquiridos é unânime, demonstrando um elevado nível de satisfação, o que demonstra que a visita cultural é do agrado de quem a visita, promovendo-se uma maior visibilidade deste espaço e termos culturais. 
Deambulando pelo santuário de panóias e pelos seus públicos: um estudo de caso.

Gráfico nº6: Análise comparativa da apreciação global da visita por sexo Comparativo da Apreciação Global da Visita pelo Sexo dos Inquiridos

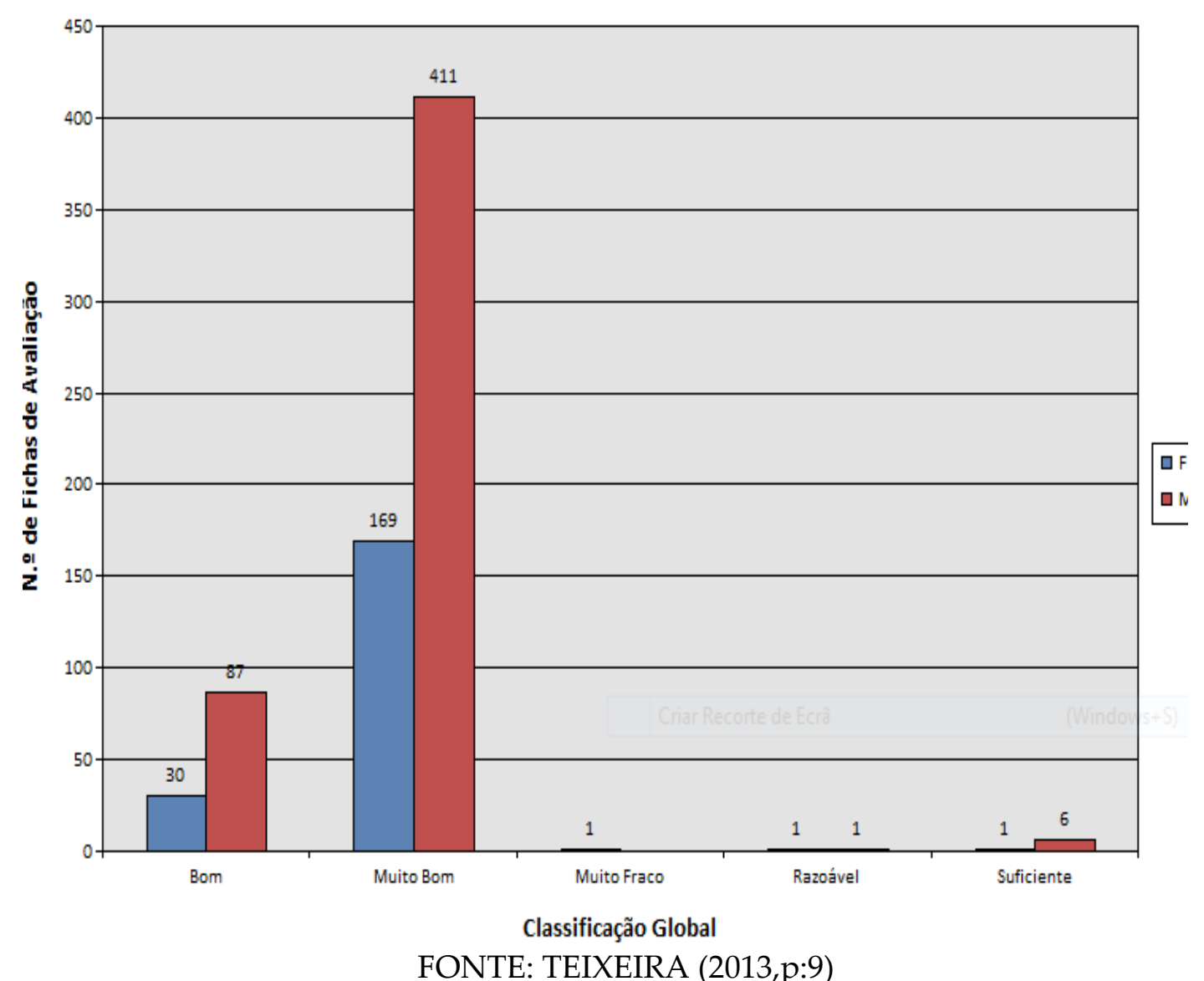

Concluímos que é coincidente a opinião dos $79 \%(n=411)$ dos inquiridos do sexo masculino e $83 \%(\mathrm{n}=169)$ do sexo feminino, avaliaram o Santuário de Panóias como sendo muito bom. Por outro lado, 17,1\% (n=87) dos inquiridos do sexo masculino e $15 \% \quad(n=30)$ do sexo feminino, consideraram o Monumento como sendo bom. Por fim, 1,1\% $(n=6)$ inquiridos do sexo masculino e $0,4 \%(n=1)$ do sexo feminino julgaram o Santuário como sendo suficiente; $0,2 \%(n=1)$ inquiridos do sexo masculino e $0,4 \%$ do sexo feminino $(\mathrm{n}=1)$ avaliaram o Monumento como razoável e apenas $0,2 \%(n=1)$ inquiridos do sexo masculino avaliaram o Santuário de Panóias como sendo muito fraco. Proporcionalmente parece que homens e mulheres mantêm o mesmo nível de avaliação e de exigência perante a 
visitante, não transparecendo maior a exigência nuns que noutros, no entanto, a conclusão não é de forma alguma fiável dada a diferença de amostragem.

\section{Gráfico n7: Análise comparativa da apreciação global por área de residência dos inquiridos Classificação Global por Distritos/Países}

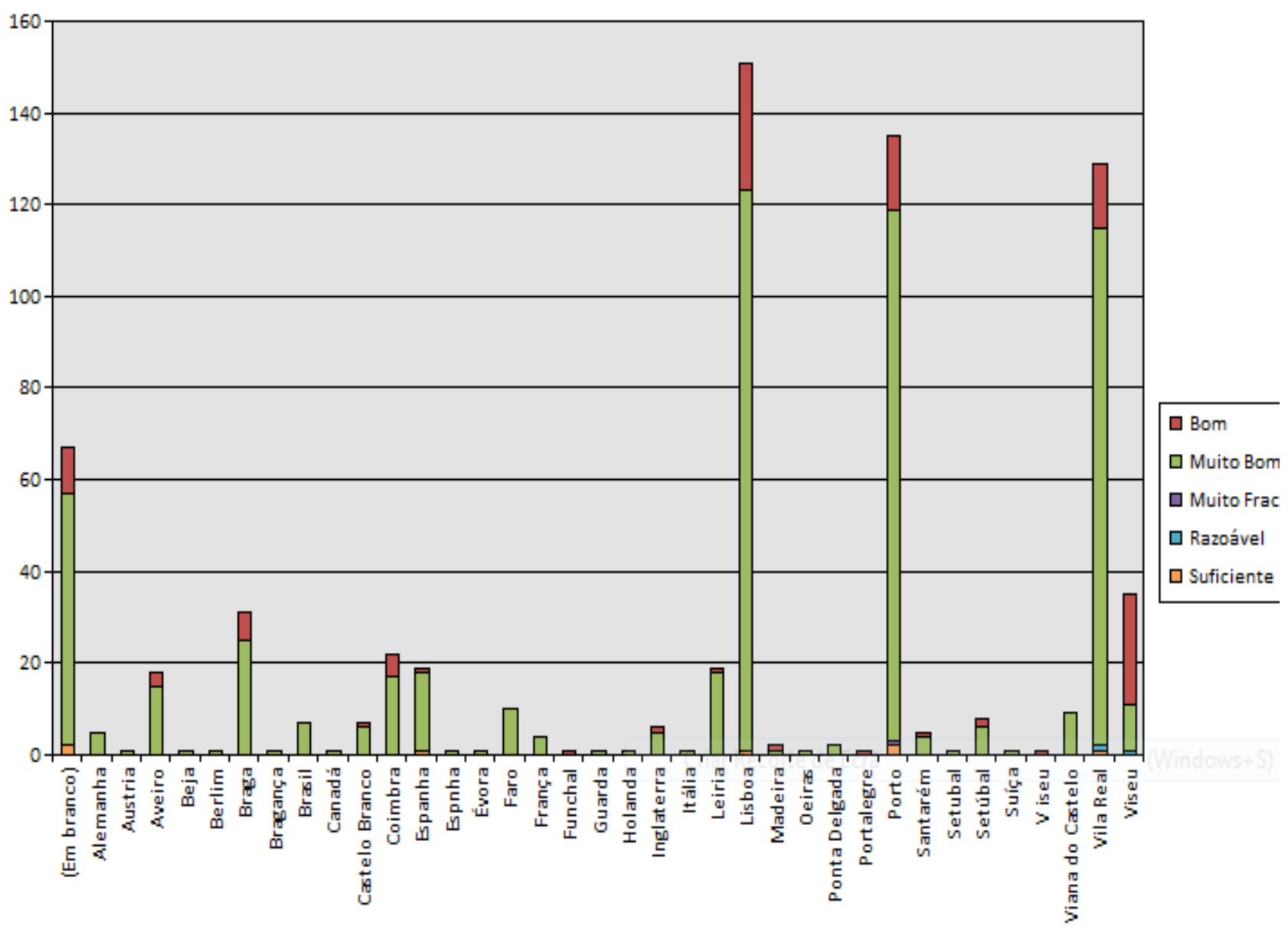

\section{Distritos/Países}

FONTE: TEIXEIRA (2013,p:10)

A partir da análise do gráfico, foi possível concluir que os 711 inquiridos que constituíram a amostra avaliaram o Monumento em termos 
Deambulando pelo santuário de panóias e pelos seus públicos: um estudo de caso.

de classificação global. Sendo assim, 8,4\% $(n=60)$ visitantes consideraramno como muito bom, $1 \%(\mathrm{n}=7)$ como bom e apenas $0,2 \%(\mathrm{n}=2)$ como suficiente.

Analisando os visitantes de origem portuguesa destacam-se primeiramente aqueles que avaliaram unanimemente o Santuário como sendo muito bom e bom. Estes provêm de Beja, Bragança, Évora, Oeiras, Ponta Delgada, Setúbal, Guarda, Viana do Castelo, Aveiro, Braga, Castelo Branco, Coimbra, Santarém, Vila Real, Viseu e Faro.

Analogamente, os visitantes estrangeiros, na sua generalidade avaliaram o Monumento na sua maioria como sendo muito bom, o que denota uma satisfação do público estrangeiro com este espaço cultural.

\section{Gráfico nº8: Análise comparativa da apreciação global por profissões dos inquiridos}

Classificação Global por Profissões

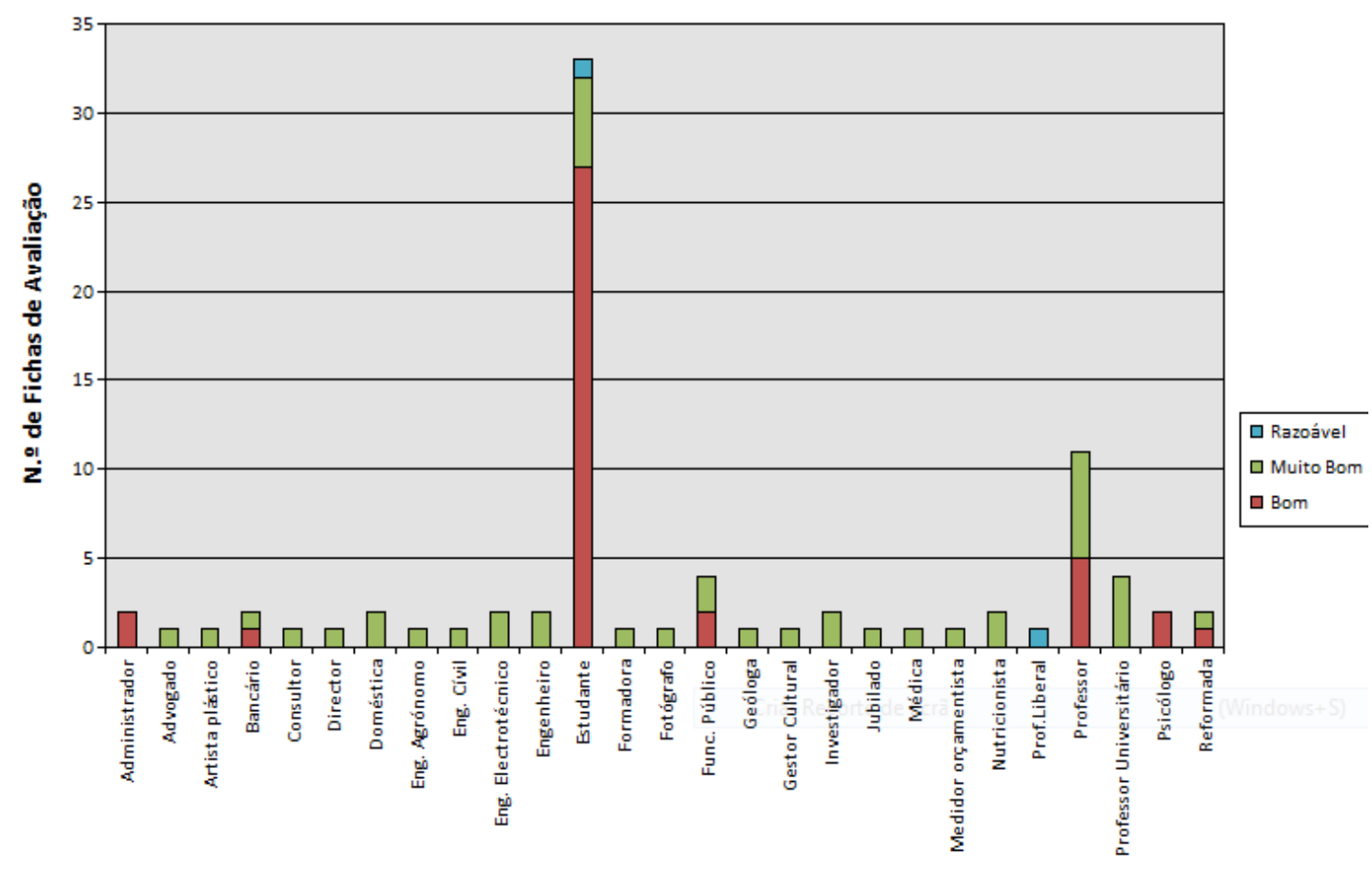

FONTE: TEIXEIRA (2013,p:11) 
Destacamos que todos consideraram o Monumento de muito bom ou bom. Apenas uma pessoa registou como razoável. Pretendemos destacar a opinião do público escolar e verificar se esta tendia em sentido inverso à generalidade das classificações. Verificou-se que se mantém inalterável a classificação de muito bom e bom, registando apenas uma opinião de razoável.

Gráfico no9: Análise comparativa da Classificação Global por ano civil

Classificação Global por Anos de Inquérito

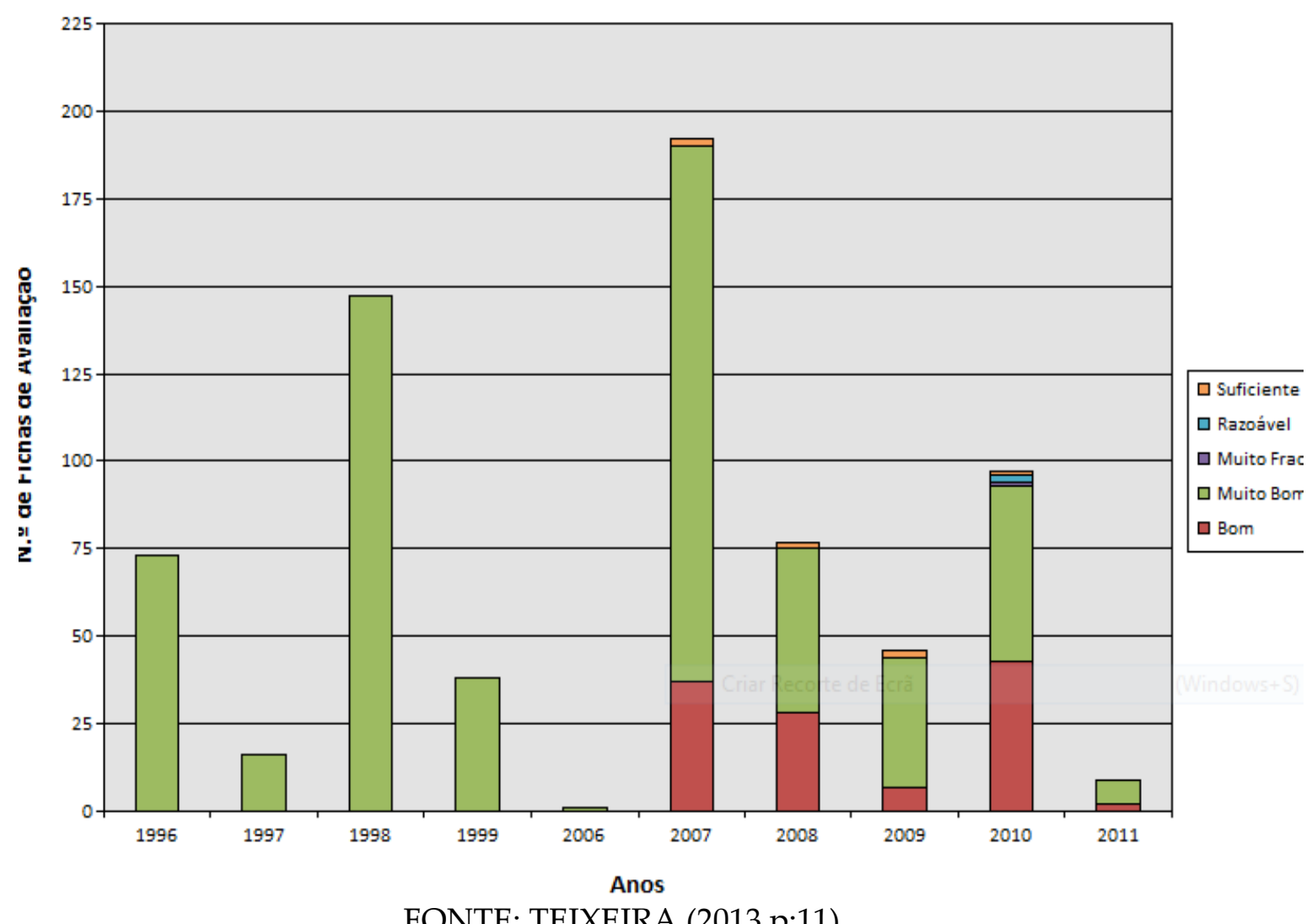

FONTE: TEIXEIRA (2013,p:11)

Mediante a análise do gráfico, concluímos que nos anos de 1996, 1997, 1998, 1999 e 2006 o Santuário de Panóias foi avaliado unanimemente por todos os visitantes como sendo muito bom, em termos de classificação global. No ano de 2007, 79\% ( $\mathrm{n}=153)$ dos visitantes avaliaram o Monumento 
Deambulando pelo santuário de panóias e pelos seus públicos: um estudo de caso.

como muito bom; $19,2 \%(n=37)$ como bom e apenas $1 \%(n=2)$ dos visitantes como suficiente. O mesmo fenómeno ocorreu em 2008.

\subsection{Pequenos relatos dos inquiridos}

A partir dos dados recolhidos pela análise dos inquéritos por questionário, foi possível categorizar um conjunto de dimensões, que estiveram na base da análise de conteúdo e da conclusão dos resultados finais deste trabalho.

Neste caso em concreto, a análise de conteúdo "oferece a possibilidade de tratar de forma metódica informações e testemunhos que apresentam um grau de profundidade e de complexidade e permite, quando incide sobre um material rico e pertinente, satisfazer as exigências do rigor metodológico e da profundidade inventiva, que nem sempre são facilmente conciliáveis" (QUIVY \& CAMPENHOUDT, 2003,p.80).

Segundo estes autores, "a análise de conteúdo tem um campo de aplicação muito vasto e os métodos utilizados obrigam o investigador a manter uma grande distância em relação a interpretações espontâneas, particularmente das suas próprias" (QUIVY \& CAMPENHOUDT, 2003,p 81).

Assim sendo, iremos citar algumas das opiniões dos nossos inquiridos acerca das várias dimensões que foram categorizadas através do método da análise de conteúdo.

Foi-nos possível concluir que a receção ao visitante foi considerada, pela maioria dos inquiridos, como sendo "muito calorosa e agradável", com "excelentes condições de tratamento aos mesmos" e "funcionários exemplares, muito conhecedores" "sempre disponíveis". O acolhimento foi ainda avaliado como sendo "excelente", "exemplar", com uma "receção de alta qualidade" e com "ótimo apoio por parte dos funcionários" do Santuário de Panóias.

A visita guiada foi avaliada como "excelente", muito bem "dirigida, organizada e orientada", bem como "motivadora", "elucidativa" e "esclarecedora" na medida em que "proporcionou novos conhecimentos", pela generalidade dos visitantes que constituíram a amostra. Destacaram o "excelente trabalho do guia, Sr. Herculano", na medida em que proporcionou aos visitantes "um acompanhamento muito personalizado" e "explicações muito esclarecedoras" acerca do Santuário de Panóias. 
Os acessos foram considerados por alguns visitantes como apresentando "boas condições" e com "fácil acesso às ruinas". No entanto uma grande maioria considerou que estes deveriam "ser melhorados", bem como deveriam existir "transportes diretos para o local".

A sinalização até ao Santuário de Panóias foi avaliada como "péssima e sem informação visível" pela grande maioria dos visitantes.

Relativamente à conservação do Monumento, conclui-se que este foi considerado pela maioria dos visitantes como sendo "um local muito bem cuidado e preservado", com "excelentes condições de tratamento do recinto envolvente".

De uma forma geral, as infraestruturas de apoio foram entendidas pela grande generalidade dos inquiridos como sendo "apropriadas" e estando em "boas condições". Algumas das mesmas poderiam ser "melhoradas" de forma a garantir um "melhor funcionamento e segurança do Santuário", relatam os visitantes.

A grande maioria dos inquiridos considerou que "deveria existir uma maior divulgação do Santuário de Panóias a nível nacional e internacional".

O apoio multimédia foi avaliado como sendo "excelente" e "muito interessante", destacando-se o filme de apresentação inicial do Santuário de Panóias avaliado como "muito interessante", "conciso", "elucidativo" e "excelente".

Finalizando, os visitantes consideraram o Monumento "um local apaixonante e de grande importância para a cultura portuguesa", referindo que "ficaram mais enriquecidos culturalmente" e "aprofundaram os seus conhecimentos sociais, culturais e religiosos".

Desta feita, fica patente que o Santuário de Panóias, é um grande pilar da cultura e sociedade portuguesa, pela sua riqueza em termos históricos e arqueológicos, remetendo-nos aos nossos antepassados, aguçando-nos desta forma, a vontade de uma investigação mais aprofundada sobre o local, como forma de projetarmos no futuro a importância de reviver e de dar a conhecer esta riqueza singular; mas também, poderá ser um elemento fulcral na projeção do turismo cultural local.

Segundo o ICOMOS (1996) “o turismo cultural é aquela forma de turismo que tem por objetivo, entre outros fins, o conhecimento de monumentos e sítios histórico-artísticos". 
Deambulando pelo santuário de panóias e pelos seus públicos: um estudo de caso.

Quando uma região consagra um Projeto de valorização cultural, a sua imagem vai ser reforçada com novas oportunidades de investimento. A realização de eventos culturais vai gerar novos recursos financeiros, quer para os cidadãos quer para as instituições locais ligadas ao comércio, restauração, turismo e lazer, possibilitando uma maior projeção da região e consequente crescimento económico.

Tal como refere a CARTA DE BRUXELAS (2009) reforça esta ideia ao referir que "o setor do Património Cultural, constitui um sector estratégico e de oportunidades para o desenvolvimento presente e futuro".

Desta forma "valorizar a Cultura implica coloca-la ao serviço da "criatividade social", convertendo-se num novo fator de desenvolvimento e de crescimento económico, em termos turísticos e hoteleiros" (MENGIN:1989,p.7).

\section{Conclusão:}

Tendo em conta a nosso objetivo de classificar os públicos da cultura que mais se destacaram durante a investigação, concluímos que quem maioritariamente visitou o Santuário de Panóias, no período analisado, foi o que Lopes (2004,p.45) designou nos seus trabalhos como Habituais, aqueles que tem menor representatividade na população portuguesa, um público escolarizado e qualificado. Assim, analogamente ao que Lopes (2004:46) referencia nos seus estudos, os públicos do Santuário de Panóias caraterizaram-se por possuir habilitações académicas elevadas, profissões qualificadas e por serem detentores de um forte capital cultural já intrínseco e enraizado.

Este desfecho vem também, ao encontro do que Santos (2003,p.77) salienta nos seus estudos: "os consumos culturais permanecem estreitamente correlacionados com o nível de instrução, e, por essa via, com a condição socioprofissional" (SANTOS,2003,p.77).

O mesmo autor, nos seus estudos obteve outra conclusão muito pertinente para o presente trabalho: "os perfis sociais dos públicos mantêm-se tendencialmente inalterados, mesmo quando, no geral, se pode verificar um aumento do volume dos mesmos" (SANTOS,2003,p.77).

A incrementação de uma maior proximidade entre os públicos menos habilitados e a "cultura da arte" requererá segundo Santos 
(1993,p.78) "um aperfeiçoamento dos processos de familiarização precoce e prolongada com os campos culturais mais seletivos".

Por outro lado, o resultado desta investigação vêm confirmar a importância destes Monumentos no processo de enriquecimento cultural dos seus visitantes, uma vez que faculta a possibilidade de adquirirem competências imprescindíveis em contextos diferenciados.

Além de potenciarem um forte enriquecimento em termos culturais, não podemos deixar e salientar a sua importância enquanto locais que complementam a função da instituição escolar, na medida em que proporcionam aos alunos um vasto leque de saberes não apreendidos em espaços formais.

É neste sentido, que reconhecemos o Santuário de Panóias como um espaço pedagógico por excelência, que reafirma a identidade local, recupera tradições atualmente em declínio, promove a cultura local e reforça a autoestima das populações residentes, constituindo um foco dinamizador de cultura e de desenvolvimento.

A valorização deste património cultural associado à sua projeção nacional e internacional serão a chave de promoção ao desenvolvimento local.

Do ponto de vista económico, esperam-se resultados ao nível do acréscimo das receitas das atividades relacionadas com o turismo; o estímulo ao aparecimento de novas empresas turísticas, promovendo e diversificando a economia local, encorajando à produção de bens e produtos locais, a melhoria da oferta de serviços e equipamentos.

Neste sentido, a "valorização de um bem com características patrimoniais é um marco no desenvolvimento e na planificação turística da região, sendo um esforço coordenado e sistemático destinado ao desenvolvimento económico e social local" (DUIS, 2010,p.11).

Os benefícios passam também pela promoção do bem-estar, pelo apoio à educação ambiental para visitantes e locais e pelo estimular do desenvolvimento e valorização da cultura.

Em suma, podemos afirmar que este espaço histórico segue os pressupostos apresentados pela Nova Museologia, assumindo-se como uma instituição com um vasto leque de funções de natureza pedagógica, cultural, social, de preservação de valores, de desenvolvimento local e de fator capaz de atrair fluxos turísticos nacionais e internacionais. 
Deambulando pelo santuário de panóias e pelos seus públicos: um estudo de caso.

Segundo Santos (2002,p.94) “o Movimento da Nova Museologia consiste num dos momentos mais significativos da Museologia Contemporânea, pelo seu caráter contestador, criativo, transformador, (...) um vetor no sentido de tornar possível a execução de processos museológicos mais ajustados às necessidades dos cidadãos, em diferentes contextos, por meio da participação, visando o desenvolvimento social".

No Seminário de Quebec, firmaram-se os seguintes pontos sobre a Nova Museologia (SANTOS,2002):

-Museologia atua com vistas a uma evolução democrática das sociedades;

- A intervenção dos museus no quadro dessa evolução passa: por um reconhecimento e uma valorização das identidades e das culturas de todos os grupos humanos inseridos no seu meio ambiente, no quadro da realidade global do mundo; por uma participação ativa desses grupos no trabalho museológico;

-Existe um movimento, caracterizado por práticas comuns, que pode assumir formas diversas, em função dos países e dos contextos, que deverão conduzir ao surgimento de um novo tipo de museu correspondente a estas novas perspetivas;

- Nestas condições, a interdisciplinaridade é a função social que conduz a uma mudança do papel e da função do museólogo, o que implica uma formação nesse sentido.

Assim, o Santuário de Panóias ao assentar a sua ação nestes pressupostos pode organizar a sua ação de forma criativa, "interagindo com os grupos sociais, aplicando as ações de pesquisa, preservação e comunicação, com a participação dos membros de uma comunidade, de acordo com as características dos diferentes contextos, tendo como objetivo principal utilizar o patrimônio cultural, como um instrumento para o exercício da cidadania e para o desenvolvimento social (SANTOS,2002,p.117)

\section{Referências:}

ALEXANDER, C. Sociologia cultural. Formas de classificación en las sociedades complejas. In Region y Sociedad. Vol.VIII,219- 226. Espanha: Editorial Anthropos, 2000. 
ALFOLDY, G. Die Mysterien von Panóias (Vila Real - Portugal), Madrider Mitteilungen, no 38, 1997, 176-246,1997.

ARGOTE, J. Memórias para a História Ecclesiástica do Arcebispado de Braga,1734.

BARATA, F. Preservando a memória do território: O parque natural de Tourega/Valverde. Évora: Edição do Centro de Ecossistemas Mediterrânicos, Universidade de Évora,1-164,2002.

BOURDIEU, P. A distinção crítica social do julgamento. Porto Alegre: Editora Zouk,2005.

BRANT, L. Faces da Cultura: Desenvolvimento Social e Investimento Cultural Privado In Revista Ide Estudos Históricos, nº 50, 1-31,2002.

CARMO, H. \& FERREIRA, M. Metodologia da Investigação: Guia para Auto aprendizagem. Lisboa: Universidade Aberta,1-354,1998.

CASSOLA,L. Turismo y ambiente.México: Ed. Trillas,1990.

COSTA, A. Dos públicos da cultura aos modos de relação com a cultura: algumas questões teóricas e metodológicas param uma agenda de investigação In $A A V V$ - Públicos da Cultura, 93-121. Lisboa: Observatório das Atividades Culturais,2004.

DAMAS, M. J. \& DE KETELE, M. Observar para avaliar. Coimbra: Livraria Almedina,1985.

DE KETELE, M. \& ROGIERS, X. Metodologia da Recolha de Dados. Fundamentos dos Métodos de Observações, de Questionários, de Entrevistas e de Estudo de documentos. Lisboa: Instituto Piaget,1-258,1999.

DOOLEY, M. Case Study Research and Theory Building. Advances in Developing Human Resources (4),335-354. U.K: SAGE,2002. 
Deambulando pelo santuário de panóias e pelos seus públicos: um estudo de caso.

DUIS U. La valorización cultural, social y turística de los recursos culturales y naturales como instrumento para la planificación turística, la conservación del Paisaje Cultural Cafetero y el desarrollo sostenible del território turístico. In Turismo y Sociedad,p.1-12. Colômbia: Facultad de Administración de Empresas Turísticas y Hoteleras,2010.

FERNANDEZ, A. Introducción a la nueva Museologia. Madrid: Alianza Editorial, S.A, 1999.

FRAGOSO, A. Avaliação de Projetos Sociais: O Caso do Projeto "Entremães". In Revista de Educação, vol. IX, no2,15-25. Lisboa: FCUL,2000.

GHIGLIONE, R. \& MATALON, B. O Inquérito: Teoria e Prática. Oeiras: Celta Editora,1-336,1993.

GOMES, R. A Distinção Banalizada? Perfis Sociais dos Públicos da Cultura. In $A A V V$., Os Públicos da Cultura,31-41. Lisboa: Observatório das Atividades Culturais,2004.

GUERREIRO, M. Educação Ambiental em Áreas Protegidas: Avaliação do Impacto de Acções Educativas em Alunos do Ensino Básico. Dissertação de mestrado (não publicada), Faculdade de Ciências do Mar e do Ambiente. Universidade do Algarve,2003.

ICOMOS (1996). Carta de Veneza: Carta Internacional sobre a Conservação e o Restauro de Monumentos e Sítios,1964. In Textos Fundamentais, no 1 , Évora.

ICOMOS (2008). Carta dos itinerários culturais. Canadá.

IGESPAR, IP. (2009). Carta de Bruxelas sobre o papel do património cultural na economia, e para a criação de uma rede europeia de seu reconhecimento e divulgação.

JORGE, V. Património e Identidade Nacional. Engenharia Civil, nº9, 1-8,2000. 
KLAMER, A. A Reevaluation of Values. In Economics. Quarterly Journal of Budapest University of Economics Sciencies, Vol. XXI, No.4, p.30-45,2000.

LATORRE, C., BETANCOURT, L. RYLANDER, A., QUADE, J. \& MATTEHI, O. A vegetation history from the arid prepuna of northern Chile (22$\left.23^{\circ} \mathrm{S}\right)$ over the last 13500 years. Chile: Laboratorio de Palinologia, Departamento de Biologia, Facultad de Ciencias, Universidad de Chile,223246,2003.

LOPES, J. A Cidade e a Cultura. Um estudo sobre práticas culturais urbanas. Porto: Edições Afrontamento,2000.

LOPES, J. Experiência Estética e Formação de Públicos. In $A A V V$., Os Públicos da Cultura, 43-54. Lisboa: Observatório das Atividades Culturais,2004.

MANONTOFF, A. Poblaciones sin fronteras y valorización del património

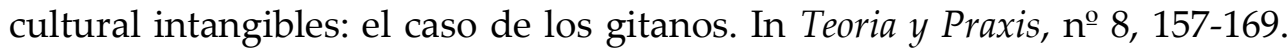
Perpignan-Via Domitia: Universidad de Perpignan-Via Domitia - Institut Catalan de Recherches en Sciences Sociales,2010.

MERRIAM, B. Case Study Research in Education: A Qualitative Approach. San Francisco: Jossey-Bass,1988.

MENGUIN, J. \& MASSON, G. Guide du développement local et du développement social. Paris: L'Harmattan, p.1-9,1989.

PALLONINO, M. \& YECKTING, F. Municipalidades Rurales del Perú y su trabajo de puesta en valor de los Activo Culturales. Perú: Instituto de Estudios perunanos, p. 1-46,2005.

PORTUGAL. Lei do Património Cultural: Lei n.o 107/2001 de 8 de Setembro.

QUIVY, R. \& CAMPENHOUDT, L. Manual de Investigação em Ciências Sociais. Lisboa: Gradiva,2003.

ROCHA, A. Avaliação de Escolas. Porto: Edições Asa,1999. 
Deambulando pelo santuário de panóias e pelos seus públicos: um estudo de caso.

SANTOS, H. A propósito dos públicos culturais: uma reflexão ilustrada para um caso português. In Revista Crítica de Ciências Sociais, nº.67, 7597,2003.

SANTOS, H. Labirintos: alguns contextos atuais dos públicos da cultura, com ilustração empírica portuguesa. In GOMES, R. (coord. técnico), Públicos da Cultura,153.162. Lisboa: Observatório das Atividades Culturais,2004.

SANTOS, M. (2002). Reflexões sobre a Nova Museologia. Cadernos de Sóciomuseologia no18,p.93-139. Lisboa: Centro de Estudos Interdisciplinares em Educação e Desenvolvimento da Universidade Lusófona de Humanidades e Tecnologias,2002.

TEIXEIRA, R. Cultura e a Diversidade de Públicos - um estudo de caso. Tese de Mestrado em Ciências da Educação, especialização em Educação Social. Porto: Universidade Portucalense Infante D. Henrique,2013.

TEIXEIRA, R. O não-formal e o informal em educação: Centralidades e periferias. In José Augusto Palhares \& Almerindo Janela Afonso (Orgs.) (2013). Atas do I colóquio internacional de ciências Sociais da Educação / III Encontro de Sociologia da Educação (3 vol.). Braga: Centro de Investigação em Educação / Universidade do Minho, 2013 ISBN: 978-989-8525-27-7.

TUCKMAN, W. Manual de Investigação em Educação. Lisboa: Fundação Calouste Gulbenkian,1-742,2000.

UNESCO. Carta de Cracóvia 2000: Principios para la conservación y retauración del patrimonio construído. Compendio del leyes sobre la proteción del patrimonio cultural de Guatemala. Guatemala: UNESCO Cultural Heritage Laws Database as the source, 2000.

UNESCO. Declaração Universal da UNESCO sobre a diversidade cultural, Adotada pela 31aㅡ Sessão da Conferência Geral da UNESCO, Paris,2001. 
UNESCO. Convenção de Faro: Quadro com Conselho da Europa relativa ao valor do Património Cultural para a sociedade. Faro: UNESCO Cultural Heritage Laws Database as the source,2005.

UNESCO. Convenção para a salvaguarda do Património Cultural Imaterial, Paris: UNESCO Cultural Heritage Laws Database as the source,2010.

VINUESA, M. Patrimonio Cultural: Valorización económica y reutilización funcional. Madrid: Universidad Complutense de Madrid,p.1-2º 2003.

VLACHOU, M . Por falar em 'novos' públicos. Disponível em www.musingonculture.com, 2011.

YACUZZI, E. El estudio de caso como metodología de investigación: teoría, mecanismos causales, validación". In Working Papers: Serie documentos del trabajo,296-306.Buenos Aires: Universidad del CEMA,2005.

YIN, R. Estudo de Caso. Planejamento e Métodos. Porto Alegre: Bookman,2005.

Enviado:

20.07.2014

Aprovado:

20.08.2014 